\title{
(C) OPEN ACCESS \\ How to evaluate premature ventricular beats in the athlete: critical review and proposal of a diagnostic algorithm
}

\author{
Domenico Corrado, ${ }^{1}$ Jonathan A Drezner, ${ }^{2}$ Flavio D'Ascenzi, ${ }^{\oplus 3}$ Alessandro Zorzi ${ }^{1}$
}

\begin{abstract}
${ }^{1}$ Department of Cardiac, Thoracic, Vascular Sciences and Public Health, University of Padova, Padova, Italy ${ }^{2}$ Stadium Sports Medicine Center, University of Washington, Seattle Washington, USA ${ }^{3}$ Department of Medical Biotechnologies, Division of Cardiology, University of Siena, Siena, Italy
\end{abstract}

\section{Correspondence to}

Professor Domenico Corrado, Department of Cardiac, Thoracic, Vascular and Public Health sciences, University of Padova, Via Giustiniani 2, 35128, Padova, Italy;

domenico.corrado@unipd.it

Accepted 15 August 2019

\section{Check for updates}

(C) Author(s) (or their employer(s)) 2019. Re-use permitted under CC BY-NC. No commercial re-use. See rights and permissions. Published by BMJ.

To cite: Corrado $D$, Drezner JA, D'Ascenzi F, et al. Br J Sports Med Epub ahead of print: [please include Day Month Year]. doi:10.1136/ bjsports-2018-100529

\section{ABSTRACT}

Although premature ventricular beats (PVBs) in young people and athletes are usually benign, they may rarely mark underlying heart disease and risk of sudden cardiac death during sport. This review addresses the prevalence, clinical meaning and diagnostic/prognostic assessment of PVBs in the athlete. The article focuses on the characteristics of PVBs, such as the morphological pattern of the ectopic QRS and the response to exercise, which accurately stratify risk. We propose an algorithm to help the sport and exercise physician manage the athlete with PVBs. We also address (1) which athletes need more indepth investigation, including cardiac MRI to exclude an underlying pathological myocardial substrate, and (2) which athletes can remain eligible to competitive sports and who needs to be excluded.

\section{INTRODUCTION}

Adolescents and young adults engaged in competitive sports activity have a risk of sudden cardiac death (SCD) that is three times higher than their sedentary counterparts. ${ }^{1}{ }^{2}$ Ventricular arrhythmias (VAs), including premature ventricular beats (PVBs), on an athlete's ECG or during an exercise ECG test may warn of increased arrhythmic risk during sports participation. ${ }^{3}$ As a consequence, PVBs on an athlete's ECG warrant an accurate clinical and secondary investigation that usually includes 24-hour ambulatory ECG monitoring, maximal exercise testing and echocardiography to rule out the presence of a cardiac disease. ${ }^{45}$

Some arrhythmic substrates, such as the apical variant of hypertrophic cardiomyopathy, segmental arrhythmogenic cardiomyopathy or non-ischaemic left ventricular scar, may be missed by routine echocardiography and detectable only by cardiac magnetic resonance (CMR) with late gadolinium enhancement (LGE) ${ }^{6-8}$ This imaging test is time-consuming, expensive and not widely available, and thus it cannot be proposed for systematic evaluation of athletes with PVBs.

This review addresses the prevalence, clinical meaning and assessment of PVBs in the athlete. The article focuses on the characteristics of PVBs, such as the morphological pattern of the ectopic QRS and the response to exercise, which are key features for risk stratification. An algorithm of clinical management of the athlete with PVBs is provided, which aims to guide sports physicians during decision-making for a more indepth work-up including CMR to exclude an underlying pathological myocardial substrate. Implications for eligibility to competitive sports activity according to current guidelines are also addressed.

\section{IS THERE A GREATER PREVALENCE OF PVBS IN ATHLETES?}

PVBs are a common ECG finding in the general population and are recorded in up to $75 \%$ of healthy individuals undergoing 24-hour ambulatory ECG monitoring, with a prevalence that increases with ageing. ${ }^{9-12}$ Whether PVBs are more frequently observed in athletes than in their sedentary counterparts is unclear.

In a group of 355 elite Italian athletes with VA and no underlying structural abnormalities, arrhythmias tended to decrease after detraining and the follow-up was uneventful, suggesting that PVBs may be a consequence of the structural and neuroautonomic remodelling of the athlete's heart. ${ }^{13}$

On the other hand, most studies comparing the prevalence of VAs on 24-hour ambulatory ECG monitoring in healthy athletes versus sedentary individuals demonstrated that only a minority of athletes exhibit frequent or complex VAs, with a prevalence that did not differ with that of their sedentary counterparts ${ }^{14-21}$ (table 1 ).

\section{WHICH CHARACTERISTICS OF PVBS CONFER A WORSE PROGNOSIS? \\ Burden}

Holter monitoring is a key test for the evaluation of the 'arrhythmic burden', that is, the number of PVBs during 24 hours and their tendency to form couplets, triplets or non-sustained ventricular tachycardia (VT). More than 500 PVBs per 24 hours on Holter monitoring may signal risk of SCD and is a diagnostic criterion for arrhythmogenic cardiomyopathy. ${ }^{22}{ }^{23}$ However, frequent PVBs are associated with a benign prognosis if an underlying disease and tachycardia-mediated left ventricular dysfunction are excluded. ${ }^{1124-28}$ Ectopic foci located in the right or left ventricular outflow tract or in the fascicles of the left bundle branch may give rise to very frequent PVBs (>10000/24 hours) that are usually isolated and occur in the absence of a pathological myocardial substrate. ${ }^{2425}$

On the other hand, systematic investigation of SCD in young people and athletes from the Veneto region of Italy and retrospective evaluation of the ECG tracings of SCD victims obtained during life demonstrated that the presence of a single PVB on basal preparticipation ECG may be a warning sign of an underlying heart disease at risk of SCD in an otherwise asymptomatic individual. ${ }^{29}$ Current consensus standards for 
Table 1 Summary of studies that compared the ventricular arrhythmic burden at 24-hour ambulatory ECG monitoring in apparently healthy athletes and sedentary controls

\begin{tabular}{|c|c|c|c|c|}
\hline Reference & $\begin{array}{l}\text { Athletes/ } \\
\text { Controls }(n)\end{array}$ & Type of athletes & Prevalence of VAs & $\begin{array}{l}\text { Imaging for underlying } \\
\text { cardiac disease }\end{array}$ \\
\hline Viitasalo et al ${ }^{18}$ & $35 / 35$ & $\begin{array}{l}\text { Young endurance }(23 \pm 6 \\
\text { years). }\end{array}$ & $\begin{array}{l}\text { Rare isolated PVBs: } 29 \% \text { of athletes and } 31 \% \text { of controls ( } p=0.79) \text {. } \\
\text { Frequent PVBs or complex VA: } 6 \% \text { of athletes and } 11 \% \text { of controls ( } p=0.67 \text { ). }\end{array}$ & N/A. \\
\hline Viitasalo et al ${ }^{19}$ & $35 / 35$ & $\begin{array}{l}\text { Adolescent athletes } \\
\text { (14-16 years). }\end{array}$ & $\geq 1$ PVB: $60 \%$ of athletes and $57 \%$ of controls $(p=0.80)$ & N/A. \\
\hline Talan et al ${ }^{17}$ & $20 / 50$ & $\begin{array}{l}\text { Young marathon runners } \\
\text { (19-29 years). }\end{array}$ & $\begin{array}{l}\geq 1 \text { PVB: } 70 \% \text { of athletes and } 50 \% \text { of controls ( } p=0.13 \text { ). } \\
>50 \text { PVBs or } \geq 1 \text { complex VA: } 10 \% \text { of athletes and } 6 \% \text { of controls ( } p=1.0 \text { ). }\end{array}$ & N/A. \\
\hline Pilcher et al ${ }^{16}$ & $80 / 0$ & $\begin{array}{l}\text { Young and middle-aged } \\
\text { runners (mean } 30 \text { years } \\
\text { old). }\end{array}$ & $\begin{array}{l}\geq 1 \text { PVB: } 50 \% \text { of athletes. } \\
>50 \text { PVBs: } 7.5 \% \text { of athletes. } \\
\text { Complex VA: } 4 \% \text { of athletes. }\end{array}$ & $\mathrm{N} / \mathrm{A}$. \\
\hline Palatini et $\mathrm{al}^{14}$ & $40 / 40$ & $\begin{array}{l}\text { Young endurance athletes } \\
\text { ( } 20 \pm 7 \text { years). }\end{array}$ & $\begin{array}{l}\geq 1 \text { PVB: } 70 \% \text { of athletes and } 55 \% \text { of controls }(p=0.17) \text {. } \\
>30 \text { PVBs or complex VA: } 13 \% \text { of athletes and } 0 \% \text { of controls }(p=0.12) \text {. }\end{array}$ & Echocardiography in all. \\
\hline Bjørnstad et al ${ }^{15}$ & $60 / 30$ & Young athletes. & $\begin{array}{l}\text { No differences between cases and controls in rare PVBs. } \\
\text { No complex forms. }\end{array}$ & N/A. \\
\hline Zorzi et al ${ }^{20}$ & $288 / 144$ & $\begin{array}{l}\text { Young competitive athletes } \\
\text { engaged in } \geq 6 \text { hours of } \\
\text { sports per week ( } 16-35 \\
\text { years). }\end{array}$ & $\begin{array}{l}\geq 1 \text { PVB: } 59 \% \text { of athletes and } 40 \% \text { of controls }(p<0.001) \\
\geq 1 \text { complex VA: } 6 \% \text { of athletes and } 8 \% \text { of controls }(p=1.0) \text {. } \\
>10 \text { PVBs or } \geq 1 \text { complex VA (primary endpoint): } 10 \% \text { of athletes and } 11 \% \text { of controls ( } p=0.62 \text { ). }\end{array}$ & $\begin{array}{l}\text { Echocardiography if } \geq 10 \\
\text { isolated PVBs or } \geq 1 \text { complex VA. } \\
\text { CMR if } \geq 500 \text { PVBs, complex VA } \\
\text { and/or exercise-induced PVBs. }\end{array}$ \\
\hline Zorzi et al ${ }^{21}$ & $134 / 134$ & $\begin{array}{l}\text { Middle-aged endurance } \\
\text { athletes engaged in } \\
\geq 6 \text { hours of sports per } \\
\text { week ( } 30-60 \text { years). }\end{array}$ & $\begin{array}{l}\geq 1 \text { PVB: } 79 \% \text { of athletes and } 73 \% \text { of controls }(p=0.25) \\
\geq 1 \text { complex VA: } 10 \% \text { of athletes and } 9 \% \text { of controls }(p=0.8) \text {. } \\
>500 \text { PVBs: } 7 \% \text { of athletes and } 5 \% \text { of controls } p=0.30) \text {. } \\
>10 \text { PVBs or } \geq 1 \text { complex VA (primary endpoint): } 26 \% \text { of athletes and } 23 \% \text { of controls }(p=0.53 \text { ). }\end{array}$ & $\begin{array}{l}\text { Exercise testing and } \\
\text { echocardiography in all. }\end{array}$ \\
\hline
\end{tabular}

Complex VAs included couplets, triplets or non-sustained ventricular tachycardia.

CMR, cardiac magnetic resonance; N/A, not available; PVBs, premature ventricular beats; VA, ventricular arrhythmias.

ECG interpretation in athletes suggest that two or more PVBs on a resting ECG are required to initiate additional investigation in an asymptomatic athlete, but even one PVB, particularly with an 'at-risk' QRS morphology, may be a significant finding. ${ }^{30}$

Complex PVBs may reflect the propensity of the arrhythmia to become sustained and potentially malignant, and hence require a more indepth clinical evaluation of the underlying substrate. Elite athletes with frequent (>2000/24hours) PVBs and non-sustained VT were reported to have a higher probability of an underlying heart disease compared with athletes with less complex PVBs. ${ }^{13}$

\section{Morphology}

The assessment of the morphology of the ectopic QRS complex on the ECG helps to identify the anatomical origin of the VA (table 2). Idiopathic PVBs are characterised by the absence of an underlying structural heart disease and a favourable prognosis and exhibit distinctive ECG patterns. ${ }^{31} 32$

The most common form of idiopathic PVBs shows an ECG pattern of the left bundle branch block (LBBB) with inferior QRS axis (also referred to as an 'infundibular' pattern). An LBBB pattern is recognised by a negative QRS complex in lead V1, while a negative QRS complex in lead aVL and positive QRS in the inferior leads (II, II, aVF) denote an inferior axis. When the ectopic QRS becomes positive beyond V3, the origin of the arrhythmia is usually the right ventricular (RV) outflow tract (figure 1A). A similar morphology but with small R-waves in V1 and earlier precordial transition (the ectopic QRS complex becomes positive by $\mathrm{V} 2$ or V3) often indicates the PVB origin from the left ventricular (LV) outflow tract (figure 1B). On Holter monitoring, the ectopic beats usually manifest as frequent

\begin{tabular}{|c|c|c|c|c|}
\hline Pattern & QRS morphology & Origin of ectopic beat & Comment & Figure \\
\hline \multicolumn{5}{|c|}{ Common patterns in athletes } \\
\hline \multirow[t]{2}{*}{ Infundibular } & $\begin{array}{l}\text { LBBB with late precordial transition (R/ } \\
\mathrm{S}=1 \text { after V3) and inferior axis. }\end{array}$ & Right ventricular outflow tract. & Usually benign. & Figure $1 \mathrm{~A}$ \\
\hline & $\begin{array}{l}\text { LBBB and inferior axis but with small } \\
\text { R-waves in } \mathrm{V} 1 \text { and early precordial } \\
\text { transition (R/S=1 by } \mathrm{V} 2 \text { or } \mathrm{V} 3) \text {. }\end{array}$ & Left ventricular outflow tract. & Usually benign. & Figure $1 \mathrm{~B}$ \\
\hline \multirow[t]{2}{*}{ Fascicular } & $\begin{array}{l}\text { Typical RBBB with superior axis and QRS } \\
<130 \text { ms. }\end{array}$ & Left posterior fascicle of the left bundle branch. & Usually benign. & Figure $1 \mathrm{C}$ \\
\hline & $\begin{array}{l}\text { Typical RBBB with inferior axis and QRS } \\
<130 \text { ms. }\end{array}$ & Left anterior fascicle of the left bundle branch. & Usually benign. & Figure 1D \\
\hline \multicolumn{5}{|c|}{ Uncommon patterns in athletes } \\
\hline & Atypical RBBB and QRS $\geq 130 \mathrm{~ms}$. & Mitral valve annulus, papillary muscles or left ventricle. & May be associated with myocardial disease. & Figures 3 and 5 \\
\hline & LBBB with superior or intermediate axis. & Right ventricular free wall or interventricular septum. & May be associated with myocardial disease. & Figure 4 \\
\hline
\end{tabular}

LBBB: negative QRS complex in lead V1.

Atypical RBBB: positive QRS complex in lead V1 not resembling a typical RBBB.

Typical RBBB: rSR' pattern in lead V1 and an S-wave wider than R-wave in lead V6.

Inferior QRS axis: positive QRS in the inferior leads (II, II, aVF).

Superior QRS axis: negative QRS in the inferior leads aVF.

Intermediate QRS axis: positive QRS complexes in both aVF and aVL.

Precordial transition: precordial lead in which the QRS complex becomes predominantly positive.

LBBB, left bundle branch block; RBBB, right bundle branch block. 


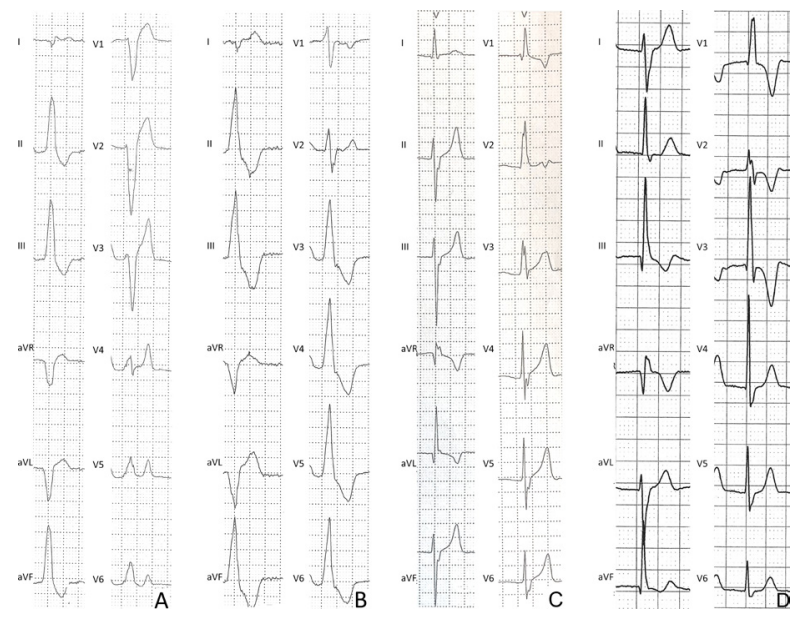

Figure 1 Morphologies of common premature ventricular beats in healthy athletes. Premature ventricular beat with negative QRS complex in V1 (left bundle branch block-like), precordial S/R transition in V4 and inferior QRS axis in the limb leads consistent with origin from the right ventricular outflow tract (A). Premature ventricular beat with negative QRS complex in V1 (left bundle branch block-like pattern), precordial S/R transition in V2/V3 and inferior QRS axis in the limb leads, suggestive of the origin from the left ventricular outflow tract (B). Premature ventricular beat with a relatively narrow QRS (120-130 ms) and typical right bundle branch block/superior axis configuration, suggestive of the origin from the posterior fascicle of the left bundle branch (C). Premature ventricular beat with a relatively narrow QRS (120-130 ms) and typical right bundle branch block/inferior axis configuration, suggestive of the origin from the anterior fascicle of the left bundle branch (D).

isolated PVBs and rare couplets, but occasionally triplets or runs of non-sustained VT may also occur. The ventricular ectopy is usually more frequent during the day than at night or following a period of exercise and is transiently suppressed by sinus tachycardia. Characteristically, during stress testing, idiopathic PVBs from the RV or LV outflow tract decrease or disappear at peak of exercise and reappear during recovery. ${ }^{33}$

Another pattern consistent with idiopathic and benign PVBs is the 'fascicular' pattern, characterised by a typical right bundle branch block (RBBB), superior QRS axis morphology and QRS duration $<130 \mathrm{~ms}$ (figure 1C). A typical RBBB is recognised by an $\mathrm{rSR}^{\prime}$ pattern in lead $\mathrm{V} 1$ and an S-wave wider than R-wave in lead V6, while a superior axis is denoted by a negative QRS in the inferior leads. This pattern features an RBBB with left anterior fascicular block and indicates the origin of the PVBs from the left posterior fascicle of the left bundle branch. Rarely, PVBs originate from the left anterior fascicle and show a typical $\mathrm{RBBB}$ and inferior axis morphology featuring an RBBB with left posterior fascicular block (figure 1D). ${ }^{34}$ Less common sources of LV idiopathic PVBs include the mitral valve annulus and the papillary muscles. In both cases, PVBs show a wide (>130 ms) QRS with an 'atypical' RBBB pattern (positive QRS complex in V1 but not resembling a typical RBBB) and variable QRS axis. ${ }^{35}$ This pattern can be similar to that occurring in the context of structural heart disease and thus requires a more comprehensive evaluation.

A study showed that in the majority of competitive athletes (68\%) with PVBs at exercise testing in the absence of an underlying disease, the ectopic QRS morphology was consistent with origin from the RV outflow tract. ${ }^{36}$ In $15 \%$, PVB morphology suggested a fascicular origin and in $9 \%$ a LV outflow tract origin.
Other morphologies such as $\mathrm{LBBB} /$ superior axis or $\mathrm{RBBB} / \mathrm{QRS}$ $>130 \mathrm{~ms}$ were rare. These findings were in agreement with another study reporting that $73 \%$ of athletes with PVBs at preparticipation evaluation showed an LBBB morphology of the ectopic QRS, 21\% had fascicular PVBs, and only 6\% had PVBs with an RBBB/QRS > 130 ms morphology. ${ }^{27}$ Similarly, in a cohort of young athletes with PVBs referred for further investigations, the majority showed an ectopic QRS morphology suggestive of an infundibular origin. ${ }^{37}$ When 12-lead 24-hour Holter monitoring was used to compare the burden and QRS morphology of VAs in 286 young athletes and 143 sedentary controls, only $6(2.1 \%)$ athletes showed $>500 \mathrm{PVBs} /$ day and 5 of them had an infundibular or fascicular morphology of the ectopic QRS. ${ }^{20}$ Similarly, in a study on 136 middle-aged endurance athletes, 8 of 10 with $>500 \mathrm{PVBs} /$ day exhibited an infundibular or fascicular morphology. ${ }^{21}$

These findings indicate that frequent PVBs in the athlete most often show either an infundibular (LBBB/inferior axis) pattern or a fascicular (typical RBBB and QRS $<130 \mathrm{~ms}$ ) morphology. Both types of PVBs arise from an automatic ventricular focus and usually occur in the absence of underlying structural heart disease. $^{33} 34$

On the contrary, other morphologies of PVBs such as LBBB/ intermediate or superior axis or RBBB/intermediate or superior axis and wide QRS are uncommon in the athlete, and when present are usually less numerous, complex (repetitive, polymorphic, short-coupled) and/or exercise-induced and may be associated with an underlying myocardial disease. Studies on athletes undergoing CMR for evaluation of VAs demonstrate that PVBs with an RBBB-like morphology and wide QRS (>130 ms) more often predict myocardial lesions (particularly non-ischaemic LV myocardial scar as evidenced by LGE). ${ }^{8203839}$

Because of the importance of the morphology of the ectopic QRS in guiding the diagnostic work-up and risk assessment, all efforts should be made to accurately characterise the ectopic QRS morphology on a 12-lead resting ECG, exercise test, or 12-lead 24-hour ambulatory ECG monitoring.

\section{Coupling interval}

Regardless of QRS morphology, short-coupled PVBs, or PVBs that are superimposed on the preceding T-wave (peak or earlier), should be regarded as a warning sign for myocardial electrical instability as a consequence of early/inhomogeneous ventricular repolarisation which may predispose to ventricular fibrillation in the absence of structural heart disease (ie, idiopathic ventricular fibrillation $)^{40}$ (figure 2). Athletes with short-coupled PVBs, particularly when associated with the ECG pattern of inferolateral early repolarisation with prominent terminal QRS slurring, should be referred to a specialist for evaluation by electrophysiological study.

\section{Relation to exercise}

PVBs induced by exercise raise clinical warning because VAs associated with heart diseases such as cardiomyopathy, myocarditis and ion channel diseases are often worsened by adrenergic stimulation. ${ }^{18203841-43}$ On the other hand, PVBs that become less frequent or disappear with increasing exercise load are usually idiopathic and benign VAs and often have an infundibular origin (ie, from the RV or LV outflow tract). ${ }^{445}$ Compared with resting ECG, exercise testing has the potential to increase the diagnostic sensitivity for identification of clinically silent arrhythmogenic heart diseases because of its ability to induce adrenergic-dependent VAs. ${ }^{46}$ In a cohort of athletes who underwent CMR for 


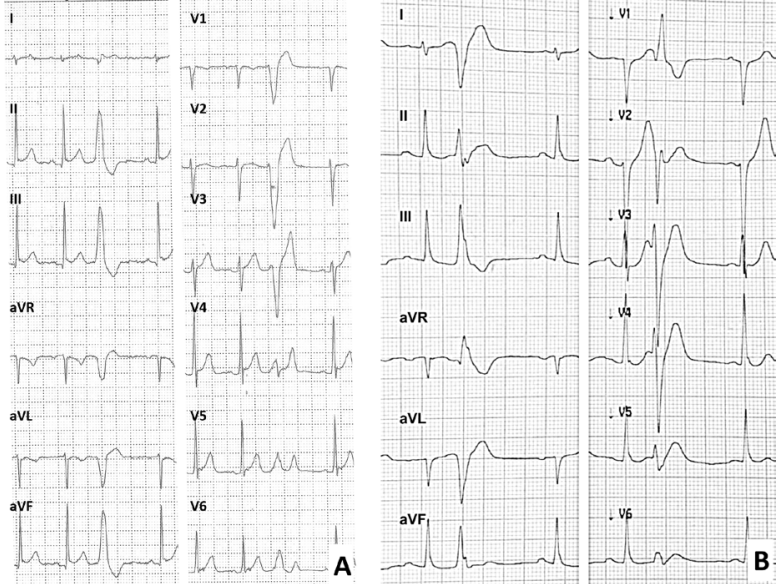

Figure 2 Coupling interval of premature ventricular beats. Normal coupling interval in a common (infundibular) pattern of premature ventricular beats (A). Short-coupled premature ventricular beats and terminal QRS slurring in the inferolateral leads followed by a flat ST segment in an athlete with idiopathic ventricular fibrillation (B).

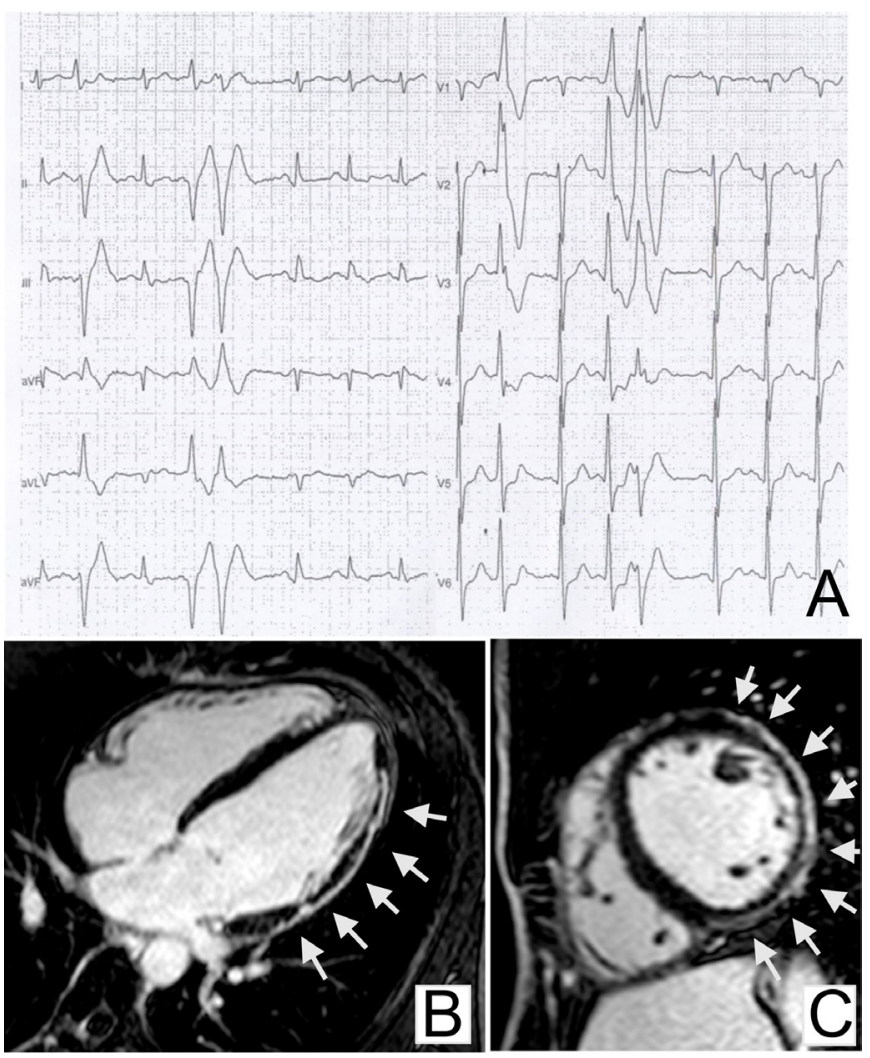

Figure 3 Premature ventricular beats with a right bundle branch block-like pattern of the ectopic QRS and underlying left ventricular myocardial disease. Frequent and coupled premature ventricular beats with a right bundle branch block/superior axis QRS morphology during exercise testing in a 42-year-old martial arts athlete (A). Long-axis view (B) and short-axis view (C) of postcontrast cardiac magnetic resonance sequences showing a subepicardial/mid-myocardial 'stria' of late gadolinium enhancement involving the anterolateral, lateral and inferolateral segments of the left ventricular wall (arrows). Modified from Zorzi et al. ${ }^{8}$ evaluation of PVBs, a higher prevalence of pathological myocardial substrates was found among athletes with exercise-induced PVBs compared with those with exercise-suppressed VAs. ${ }^{38}$ In particular, exercise-induced complex VAs with an RBBB morphology and QRS $>130 \mathrm{~ms}$ were the strongest predictors of pathological findings on $\mathrm{CMR}(\mathrm{OR}=5.3)$ (figure 3). Therefore, clinicians should evaluate the inducibility of PVBs and how the PVBs respond to maximal exercise testing when aiming to identify athletes with an arrhythmic myocardial substrate. In particular, PVBs occurring (or persisting) at high workload and/ or exercise-induced complex PVBs may signal underlying heart disease.

Exercise-induced PVBs with multiple morphologies of the ectopic QRS, especially with beat-to-beat alternating morphologies (the so called 'bi-directional' pattern), are associated with a high risk for effort-related SCD. Indeed, this arrhythmic pattern may be expression of an inherited ion channel disease, catecholaminergic polymorphic VT, which predisposes to adrenergic-dependent VAs which can degenerate into ventricular fibrillation. ${ }^{43}$

\section{Response to detraining}

A previous study demonstrated that in the majority of athletes with PVBs and no underlying heart disease, the arrhythmia decreased or disappeared after a period of 3-6 months of detraining. While athletes with a persistence of PVBs were deemed not eligible for competitive sports, those who had a reduction in the burden of PVBs after detraining were allowed to resume competitive sports activity and had an uneventful longterm follow-up. ${ }^{36}$ These findings suggest that the prognosis of exercise-induced PVBs that are unrelated to a structural heart disease and resolve with detraining is favourable.

However, other studies showed conflicting results and called into question the prognostic value of detraining athletes with PVBs. Biffi et al ${ }^{47}$ demonstrated that healthy Olympic athletes with frequent PVBs most often show reduction or disappearance of the arrhythmia with detraining. This finding has been interpreted as support that PVBs are part of the physiological spectrum of electrical and structural adaptive changes of the heart to physical exercise (the so-called 'athlete's heart'). On the other hand, the same authors in subsequent studies found that (1) retraining athletes did not cause PVBs to relapse ${ }^{48}$ and (2) there was no correlation between the arrhythmic burden and the degree of training-induced left ventricular hypertrophy. ${ }^{49}$ Delise et $a l^{50}$ did not find any differences in the behaviour of VA (persistence or reduction) during follow-up in a group of athletes who continue training versus a group of athletes who interrupted sport activity.

\section{HOW TO EVALUATE THE ATHLETE WITH PVBS}

Table 3 classifies PVBs in the athlete based on number, morphological pattern, complexity, response to exercise and clinical manifestations. The table provides criteria to distinguish 'common' and benign PVBs from 'uncommon' PVBs that are associated with a higher risk of cardiac pathology. This approach is pivotal to the appropriate management of an athlete with PVBs to guide arrhythmic risk stratification and the diagnostic work-up to confirm (or exclude) underlying heart disease.

The presence of PVBs on an athlete's resting ECG or during exercise testing does not lead to a diagnosis of a heart disorder in itself, but it should launch a cascade of further cardiovascular evaluations to confirm (or exclude) cardiac pathology. The international criteria for ECG interpretation in athletes suggested 
Table 3 Classification and risk stratification of premature ventricular beats in the athlete

\begin{tabular}{|c|c|c|}
\hline & Common & Uncommon \\
\hline \multicolumn{3}{|l|}{ PVB characteristics } \\
\hline $\begin{array}{l}\text { Ectopic QRS } \\
\text { morphology }\end{array}$ & $\begin{array}{l}\text { LBBB/inferior axis, typical } \\
\text { RBBB and narrow QRS } \\
\text { (<130 ms) }\end{array}$ & $\begin{array}{l}\text { LBBB/intermediate or } \\
\text { superior axis, atypical RBBB } \\
\text { and wide QRS ( } \geq 130 \mathrm{~ms} \text { ) }\end{array}$ \\
\hline $\begin{array}{l}\text { Response to exercise } \\
\text { testing }\end{array}$ & Decrease/suppression & Persistence/increase \\
\hline Complexity of PVBs & Isolated, monomorphic & Repetitiveł, polymorphic \\
\hline Short coupling interval* & No & Yes \\
\hline \multicolumn{3}{|l|}{ Clinical findings } \\
\hline Symptoms & No & Yes \\
\hline $\begin{array}{l}\text { Family history of } \\
\text { premature SCD }+ \text { or } \\
\text { cardiomyopathy }\end{array}$ & No & Yes \\
\hline $\begin{array}{l}\text { Other ECG } \\
\text { abnormalities }\end{array}$ & No & Yes \\
\hline Imaging abnormalities & No & Yes \\
\hline
\end{tabular}

*PVBs are superimposed on the preceding T-wave peak or earlier (ie, R on T). tPremature sudden cardiac death (SCD) is defined as that occurring before 40 years of age in men and before 50 years old in women.

‡Couplets, triplets or non-sustained ventricular tachycardia.

$\mathrm{LBBB}$, left bundle branch block; PVBs, premature ventricular beats; RBBB, right bundle branch block.
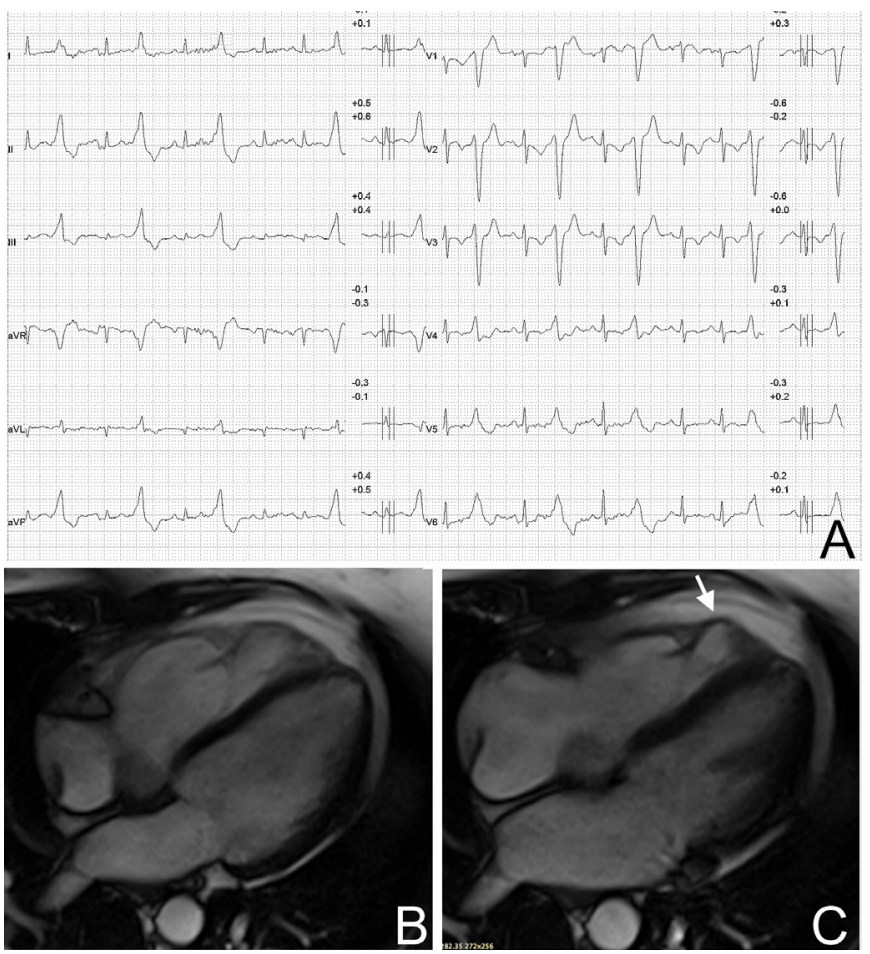

Figure 4 Premature ventricular beats with a left bundle branch block-like pattern of the ectopic QRS and underlying right ventricular myocardial disease. Premature ventricular beats with a left bundle branch block/intermediate axis pattern, associated with ECG abnormalities (low QRS voltages in the limb leads and negative T-waves in V1-V3 in non-ectopic beats), which increased during exercise testing in a 34-year-old female runner (A). Cine cardiac magnetic resonance sequences (four-chamber view) revealed right ventricular dilation with hypertrabeculation (diastolic frame) (B) and dyskinesia (arrow) of the right ventricular free wall (systole frame) consistent with arrhythmogenic cardiomyopathy (C). that further evaluation is warranted when $\geq 2$ PVBs are recorded on a resting 12-lead ECG. ${ }^{30}$ However, even a single PVB may deserve attention especially in the presence of one or more of these five features: (1) positive family history of premature SCD or cardiomyopathy, (2) relevant symptoms, (3) associated ECG abnormalities, (4) uncommon PVB morphology (table 2) and (5) short coupling interval.

\section{Electrocardiography}

The ECG is an essential part of the evaluation of athletes with PVBs because concomitant repolarisation/depolarisation abnormalities may provide important information on a possible underlying cardiomyopathy or channelopathy. 3051

The most relevant ECG abnormalities which are consistent with an at-risk heart muscle disorder include repolarisation abnormalities such as T-wave inversion and ST segment depression, pathological Q-waves, intraventricular conduction disturbances, ventricular pre-excitation and a long QT interval. These ECG abnormalities are classified by current recommendations for interpretation of the athlete's ECG as abnormal and training-unrelated ECG findings that warrant additional investigation to exclude myocardial disease. ${ }^{3} 3051$ The association between a PVB with a LBBB morphology and other ECG abnormalities such as T-wave inversion, prolonged $S$-wave upstroke $(\geq 55 \mathrm{~ms}$ from the nadir of the S-wave to the end of the QRS complex in leads V1-V3) or a epsilon wave (small positive deflection or notch between the end of the QRS complex and onset of the T-wave in leads V1-V3) in the non-ectopic beats is highly suggestive of arrhythmogenic cardiomyopathy ${ }^{22}{ }^{52-54}$ (figure 4). On the other hand, PVBs with an RBBB pattern $>130 \mathrm{~ms}$ and negative T-waves in the left precordial leads (V5-V6) in the non-ectopic beats should raise the suspicion of a LV myocardial disease, such as dilated cardiomyopathy, non-ischaemic LV scar (figure 3), hypertrophic cardiomyopathy, left-dominant arrhythmogenic cardiomyopathy or arrhythmic mitral valve prolapse (figure 5). ${ }^{8295}$ Athletes with PVBs and concomitant repolarisation/depolarisation abnormalities require an indepth cardiovascular evaluation aimed to confirm (or exclude) such heart muscle diseases.

\section{Exercise testing}

Exercise testing is part of the first-line evaluation of athletes with PVBs. It allows assessment of the behaviour of PVBs with increasing workload and other abnormal findings suggestive of an underlying cardiac disease, such as ST segment changes, abnormal blood pressure response to exercise or an impaired exercise capacity. Exercise testing in the athlete should not be stopped at $85 \%$ of the theoretical maximal heart rate but continued until exhaustion in order to increase the test sensitivity of unmasking adrenergic-dependent PVBs or myocardial ischaemia occurring at high workload.

\section{Echocardiography}

Echocardiography represents the first test for investigating a possible structural heart disease in athletes with PVBs. Echocardiography aims to assess the systolic function (both global and regional), the diastolic filling pattern and ventricular wall thickness and chamber size, as well as to evaluate for wall motion abnormalities suggestive of ischaemic heart disease, valvular abnormalities, congenital heart diseases and cardiomyopathies. Echocardiography is also the basal screening modality for characterisation of the coronary artery take-off from the aorta and offers the potential to detect congenital coronary artery 


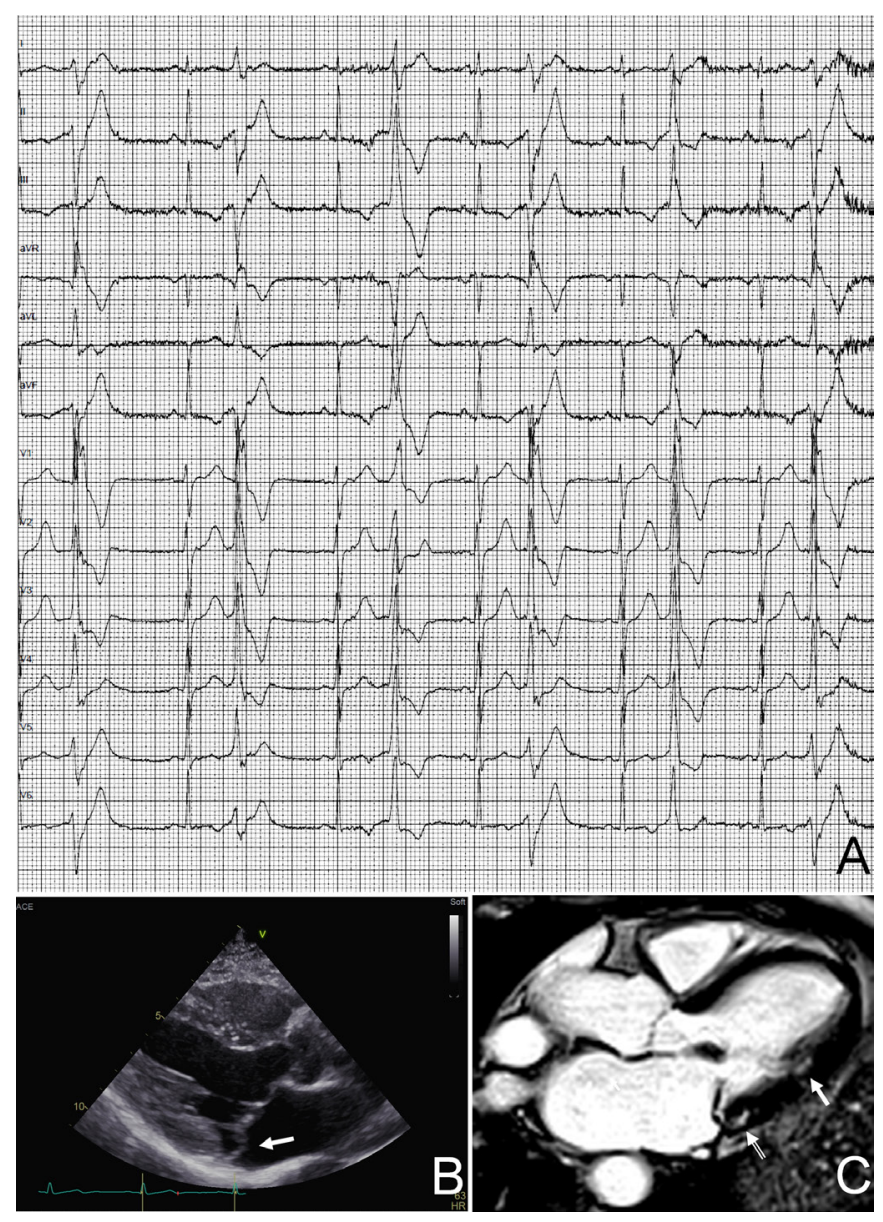

Figure 5 Premature ventricular beats in an athlete with arrhythmic mitral valve prolapse. Premature ventricular beats with a right bundle branch block morphology and variable QRS axis, suggesting multiple ectopic foci in the left ventricular myocardium (A). Echocardiography (long-axis parasternal view) showing thickened and prolapsing mitral valve leaflets (arrow) (B). Postcontrast cardiac magnetic resonance sequence (apical four-chamber view) showing potentially arrhythmogenic areas of myocardial fibrosis/late gadolinium enhancement which are localised behind the posterior leaflet of the mitral valve (open arrow) and at the implant of the posterolateral papillary muscle (arrow) (C).

anomalies which are leading causes of ischaemia-induced VAs and SCD in the athlete. ${ }^{56}$ Zeppilli et $a l^{57}$ and Pelliccia et $a l^{58}$ demonstrated the feasibility of echocardiographic imaging of the origin of coronary arteries in the vast majority of young athletes who usually have an optimal ultrasound window with excellent image quality.

However, echocardiography shows significant limitations in the evaluation of athletes with PVBs due to its inability to detect some conditions potentially associated with SCD during sports such as intramyocardial course of coronary arteries, atherosclerotic coronary artery stenosis, apical hypertrophy or segmental subepicardial-mediomural myocardial fibrosis.

\section{Cardiac magnetic resonance}

CMR provides additional diagnostic value to echocardiography in athletes with PVBs. ${ }^{39}$ It allows accurate evaluation of cavity dimensions, wall thickness, global systolic function and regional wall motion abnormalities of both ventricles; in addition, it has the unique power to identify and quantify myocardial

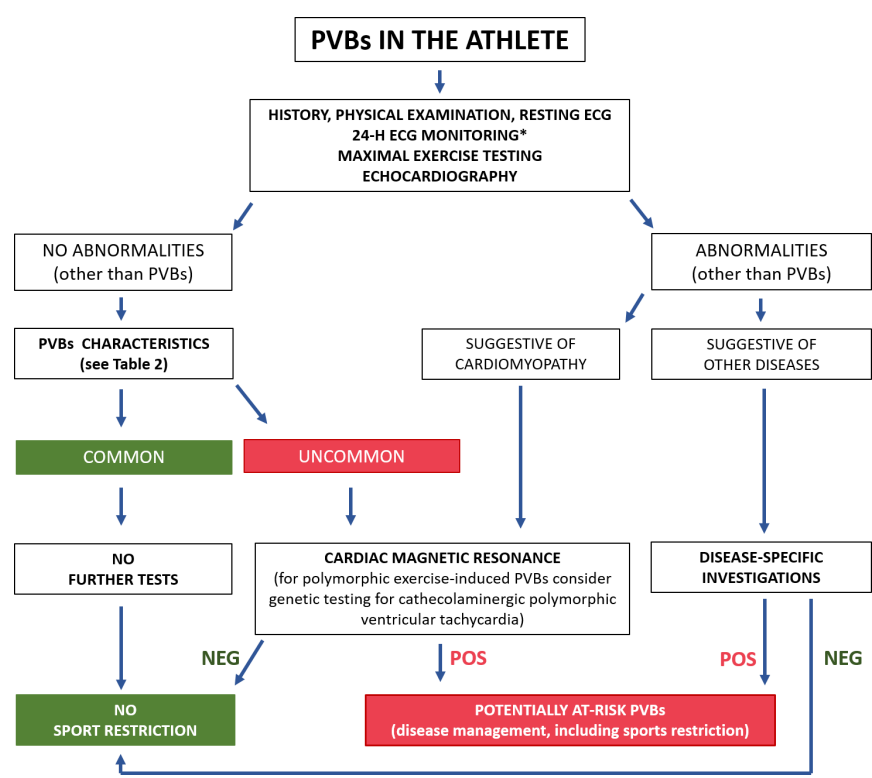

Figure 6 Proposed algorithm for evaluation of athletes with premature ventricular beats. *24-hour ECG monitoring should ideally have 12-lead configuration and include a training session. NEG, negative; POS, positive; PVBs, premature ventricular beats.

tissue abnormalities such as oedema, fatty infiltration or replacing-type fibrosis through LGE technique. It has been reported that contrast-enhanced CMR is able to identify the presence of a non-ischaemic LV scar, otherwise missed by echocardiography, in a sizeable proportion of athletes with apparently unexplained PVBs or repolarisation abnormalities. ${ }^{20} 2138395960$ These scars are undetectable by wall motion analysis on echocardiography because they affect a segmental area of the ventricular musculature and spare the subendocardial wall layer that mostly contributes to myocardial thickening. ${ }^{61}$ As a consequence, CMR has become a key test for the evaluation of athletes with PVBs with high-risk morphological features on resting 12-lead ECG or exercise testing. CMR is also valuable when echocardiography is inconclusive, particularly if the ectopic QRS is wide (>130 ms) and shows an RBBB/superior axis pattern, which suggests origin from the inferolateral left ventricular wall. The probability to detect an underlying myocardial abnormality on CMR in athletes with PVBs is highest when they are complex and/ or exercise-induced. ${ }^{38}$ According to current consensus standards for ECG interpretation in athletes, additional evaluation with CMR is also indicated in athletes with $\geq 2000$ PVBs per 24 hours (regardless of the PVB morphology, complexity and response to exercise). This recommendation for CMR, which is merely based on the number of PVBs, may be out of date in light of more modern scientific perspectives on arrhythmic risk stratification in the athlete.

\section{SUMMARISING THE EVALUATION}

Figure 6 presents a practical flow chart for the clinical evaluation of the athlete with PVBs. First-line examinations include echocardiography, maximal exercise testing and 24-hour ambulatory ECG monitoring (ideally with a 12-lead configuration and inclusion of a training session). If these exams are abnormal, further tests depend on the suspected disease. The work-up of athletes with negative results of first-line examinations relies on the characteristics of PVBs. Athletes with a 'common' PVB pattern (table 3) do not require further testing and can be considered eligible for 
competitive sports, unless the clinical suspicion of disease remains high because of serious arrhythmic symptoms or a positive family history for SCD or cardiomyopathy.

Athletes with an 'uncommon' PVB pattern should undergo a contrast-enhanced CMR, regardless of symptoms or familial background or the results of first-line examinations, to rule out a concealed myocardial substrate at risk of malignant arrhythmic events during sports activity. Other examinations such as coronary CT or coronary angiography may be considered in selected middle-aged and senior athletes with exercise-induced PVBs and a high coronary risk score.

PVBs that occur during exercise testing and become complex with increasing workload may be a sign of catecholaminergic polymorphic VT whose definitive diagnosis (or exclusion) relies on molecular genetic testing for pathogenetic mutations of the ryanodinic receptor or calsequestrin genes. ${ }^{43}$

According to the proposed management flow chart of athletes with PVBs, further diagnostic evaluation with sophisticated (and costly) imaging tests or molecular genetic testing is limited to the small subset of athletes with 'uncommon' PVB characteristics, which may reflect a clinically concealed but potentially lethal heart disease, whose diagnosis may be missed by routine tests. On the contrary, recording most 'common' PVBs such as those with an 'infundibular' or 'fascicular' pattern should provide reassurance to continue to participate in competitive sports, provided that first-line examinations are normal, the athlete is asymptomatic and family history for inherited cardiac disease or premature SCD is negative. The use of this modern and detailed approach to PVB interpretation and the subsequent diagnostic work-up is expected to improve the cardiovascular care for athletes before participation in sports.

\section{IMPLICATIONS FOR COMPETITIVE SPORTS ELIGIBILITY}

The presence of an underlying heart disease is a key prognostic factor and the most important determinant regarding eligibility recommendations for competitive sports activity for athletes with PVBs.

According to the 2015 recommendations of the American Heart Association and the American College of Cardiology, athletes with PVBs or couplets in the absence of structural heart disease should be considered eligible for all competitive sports. The recommended intensity of exercise is to remain under the threshold for the occurrence of arrhythmia-related symptoms such as presyncope, dizziness or dyspnoea. If at-risk cardiovascular disease is identified, only sports activities at low cardiovascular demand are allowed. ${ }^{5}$

The 2006 consensus document of the Working Group on Sports Cardiology of the European Society of Cardiology provided more strict criteria for eligibility and recommended to exclude from competitive sports activity athletes with $>2000 \mathrm{PVBs} /$ day and complex or exercise-induced PVBs even in the absence of an underlying structural heart disease, unless they disappear after 3-6 months of detraining. ${ }^{4}$ However, these recommendations appear out of date considering more recent scientific data on the morphology and clinical meaning of PVBs.

\section{CONCLUSIONS}

PVBs detected on the athlete's ECG should prompt an accurate clinical work-up aimed to exclude relevant-potentially lethalcardiac disease. All efforts should be made to record the 12-lead ECG pattern of PVBs to assess the morphology of the ectopic beats. First-line investigations include an echocardiogram and 24-hour Holter monitoring (with 12-lead configuration if available), which includes an exercise session and maximal exercise testing, to evaluate the tendency of the arrhythmia to worsen during effort. The decision for more indepth investigations, with particular reference to the use of CMR for excluding myocardial tissue abnormalities otherwise missed by echocardiography, should be guided by the assessment of morphology, complexity and exercise inducibility of PVBs rather than by their absolute number on 24-hour Holter monitoring.

\section{What is already known}

- Premature ventricular beats (PVBs) in athletes warrant an accurate clinical work-up to exclude a heart disease at risk of sudden cardiac death during sports; however, in the majority of cases, PVBs are unrelated to an underlying pathological substrate (idiopathic).

\section{What are the new findings}

- Differentiating between common idiopathic PVBs and potentially malignant arrhythmias should be based on multiple features (particularly the morphology of the ectopic QRS complex) rather than just the arrhythmic burden (number of PVBs) on 24-hour ECG monitoring.

- If clinicians use the proposed algorithm for clinical workup of athletes with PVBs (see figure 6), further diagnostic evaluation with sophisticated (and costly) imaging tests or molecular genetic testing will be limited to a very small subset of athletes with 'uncommon' PVB characteristics.

Contributors All authors contributed to writing and reviewing the manuscript.

Funding Supported by BIRD (Budget for Integrated Department Research Project) 2016-2018, University of Padova, Italy.

Competing interests None declared.

Patient consent for publication Not required.

Provenance and peer review Not commissioned; externally peer reviewed.

Open access This is an open access article distributed in accordance with the Creative Commons Attribution Non Commercial (CC BY-NC 4.0) license, which permits others to distribute, remix, adapt, build upon this work non-commercially, and license their derivative works on different terms, provided the original work is properly cited, appropriate credit is given, any changes made indicated, and the use is non-commercial. See: http://creativecommons.org/licenses/by-nc/4.0/.

\section{REFERENCES}

1. Corrado D, Basso C, Rizzoli G, et al. Does sports activity enhance the risk of sudden death in adolescents and young adults? J Am Coll Cardiol 2003;42:1959-63.

2. Maron BJ, Pelliccia A. The heart of trained athletes: cardiac remodeling and the risks of sports, including sudden death. Circulation 2006;114:1633-44.

3. Mont L, Pelliccia A, Sharma S, et al. Pre-participation cardiovascular evaluation for athletic participants to prevent sudden death: position paper from the EHRA and the EACPR, branches of the ESC. endorsed by APHRS, Hrs, and SOLAECE. Eur J Prev Cardiol 2017;24:41-69.

4. Heidbüchel H, Corrado D, Biffi A, et al. Recommendations for participation in leisure-time physical activity and competitive sports of patients with arrhythmias and potentially arrhythmogenic conditions. Part II: ventricular arrhythmias, channelopathies and implantable defibrillators. Eur J Cardiovasc Prev Rehabil 2006;13:676-86.

5. Zipes DP, Link MS, Ackerman MJ, et al. Eligibility and Disqualification recommendations for competitive athletes with cardiovascular abnormalities: Task force 9: arrhythmias and conduction defects: a scientific statement from the American heart association and American College of cardiology. Circulation 2015;132:e315-25.

6. Moon JCC, Fisher NG, McKenna WJ, et al. Detection of apical hypertrophic cardiomyopathy by cardiovascular magnetic resonance in patients with nondiagnostic echocardiography. Heart 2004;90:645-9.

7. Sen-Chowdhry S, Syrris P, Prasad SK, et al. Left-dominant arrhythmogenic cardiomyopathy: an under-recognized clinical entity. J Am Coll Cardiol 2008;52:2175-87. 
8. Zorzi A, Perazzolo Marra M, Rigato I, et al. Nonischemic left ventricular scar as a substrate of life-threatening ventricular arrhythmias and sudden cardiac death in competitive athletes. Circulation 2016;9.

9. Engel $\mathrm{G}$, Cho $S$, Ghayoumi $A$, et al. Prognostic significance of PVCs and resting heart rate. Ann Noninv Electrocard 2007;12:121-9.

10. Hingorani P, Karnad DR, Rohekar P, et al. Arrhythmias seen in baseline 24-hour Holter ECG recordings in healthy normal volunteers during phase 1 clinical trials. J Clin Pharmacol 2016:56:885-93.

11. Kennedy HL, Whitlock JA, Sprague MK, et al. Long-term follow-up of asymptomatic healthy subjects with frequent and complex ventricular ectopy. N Engl J Med 1985;312:193-7.

12. von Rotz $M$, Aeschbacher $\mathrm{S}$, Bossard $M$, et al. Risk factors for premature ventricular contractions in young and healthy adults. Heart 2017;103:702-7.

13. Biffi A, Pelliccia A, Verdile L, et al. Long-term clinical significance of frequent and complex ventricular tachyarrhythmias in trained athletes. J Am Coll Cardiol 2002;40:446-52.

14. Palatini P, Maraglino G, Sperti G, et al. Prevalence and possible mechanisms of ventricular arrhythmias in athletes. Am Heart J 1985;110:560-7.

15. Bjørnstad $H$, Storstein $L$, Meen $H D$, et al. Ambulatory electrocardiographic findings in top athletes, athletic students and control subjects. Cardiology 1994;84:42-50.

16. Pilcher GF, Cook AJ, Johnston BL, et al. Twenty-four-hour continuous electrocardiography during exercise and free activity in 80 apparently healthy runners. Am J Cardiol 1983;52:859-61.

17. Talan DA, Bauernfeind RA, Ashley WW, et al. Twenty-four hour continuous ECG recordings in long-distance runners. Chest 1982;82:19-24.

18. Viitasalo MT, Kala R, Eisalo A. Ambulatory electrocardiographic recording in endurance athletes. Br Heart J 1982;47:213-20.

19. Viitasalo MT, Kala R, Eisalo A. Ambulatory electrocardiographic findings in young athletes between 14 and 16 years of age. Eur Heart J 1984;5:2-6.

20. Zorzi A, De Lazzari $M$, Mastella $G$, et al. Ventricular arrhythmias in young competitive athletes: prevalence, determinants, and underlying substrate. J Am Heart Assoc 2018;7.

21. Zorzi A, Mastella G, Cipriani A, et al. Burden of ventricular arrhythmias at 12-lead 24hour ambulatory ECG monitoring in middle-aged endurance athletes versus sedentary controls. Eur J Prev Cardiol 2018;25:2003-11.

22. Novak J, Zorzi A, Castelletti S, et al. Electrocardiographic differentiation of idiopathic right ventricular outflow tract ectopy from early arrhythmogenic right ventricular cardiomyopathy. Europace 2017;19:622-8.

23. Marcus Fl, McKenna WJ, Sherrill D, et al. Diagnosis of arrhythmogenic right ventricular cardiomyopathy/dysplasia: proposed modification of the task force criteria. Circulation 2010;121:1533-41.

24. Niwano S, Wakisaka Y, Niwano H, et al. Prognostic significance of frequent premature ventricular contractions originating from the ventricular outflow tract in patients with normal left ventricular function. Heart 2009;95:1230-7.

25. Ventura R, Steven D, Klemm HU, et al. Decennial follow-up in patients with recurrent tachycardia originating from the right ventricular outflow tract: electrophysiologic characteristics and response to treatment. Eur Heart J 2007;28:2338-45.

26. Califf RM, McKinnis RA, Burks J, et al. Prognostic implications of ventricular arrhythmias during 24 hour ambulatory monitoring in patients undergoing cardiac catheterization for coronary artery disease. Am J Cardiol 1982;50:23-31.

27. Delise P, Sitta N, Lanari $E$, et al. Long-term effect of continuing sports activity in competitive athletes with frequent ventricular premature complexes and apparently normal heart. Am J Cardiol 2013;112:1396-402.

28. Gaita F, Giustetto C, Di Donna P, et al. Long-Term follow-up of right ventricular monomorphic extrasystoles. J Am Coll Cardiol 2001:38:364-70.

29. Corrado D, Basso C, Schiavon M, et al. Screening for hypertrophic cardiomyopathy in young athletes. N Engl J Med 1998:339:364-9.

30. Drezner JA, Sharma S, Baggish A, et al. International criteria for electrocardiographic interpretation in athletes: consensus statement. Br J Sports Med 2017:51:704-31.

31. Yamada T. Idiopathic ventricular arrhythmias: relevance to the anatomy, diagnosis and treatment. J Cardiol 2016;68:463-71.

32. Luebbert J, Auberson D, Marchlinski F. Premature ventricular complexes in apparently normal hearts. Card Electrophysio/ Clin 2016;8:503-14

33. John RM, Stevenson WG. Outflow tract premature ventricular contractions and ventricular tachycardia: the typical and the challenging. Card Electrophysiol Clin 2016;8:545-54.

34. Sung R, Scheinman M. Spectrum of fascicular arrhythmias. Card Electrophysio/ Clin 2016:8:567-80.

35. Al'Aref SJ, Ip JE, Markowitz SM, et al. Differentiation of papillary muscle from fascicular and mitral annular ventricular arrhythmias in patients with and without structural heart disease. Circ Arrhythm Electrophysiol 2015;8:616-24.
36. Verdile L, Maron BJ, Pelliccia A, et al. Clinical significance of exercise-induced ventricular tachyarrhythmias in trained athletes without cardiovascular abnormalities. Heart Rhythm 2015;12:78-85.

37. Steriotis AK, Nava A, Rigato I, et al. Noninvasive cardiac screening in young athletes with ventricular arrhythmias. Am J Cardiol 2013;111:557-62.

38. Cipriani A, Zorzi A, Sarto P, et al. Predictive value of exercise testing in athletes with ventricular ectopy evaluated by cardiac magnetic resonance. Heart Rhythm 2019;16:239-48.

39. Nucifora G, Muser D, Masci PG, et al. Prevalence and prognostic value of concealed structural abnormalities in patients with apparently idiopathic ventricular arrhythmias of left versus right ventricular origin: a magnetic resonance imaging study. Circ Arrhythm Electrophysiol 2014;7:456-62.

40. Antzelevitch C, Yan G-X, Ackerman MJ, et al. J-Wave syndromes expert consensus conference report: emerging concepts and gaps in knowledge. Heart Rhythm 2016;13:e295-324.

41. Gimeno JR, Tomé-Esteban M, Lofiego C, et al. Exercise-Induced ventricular arrhythmias and risk of sudden cardiac death in patients with hypertrophic cardiomyopathy. Eur Heart J 2009:30:2599-605.

42. Heidbüchel H, Hoogsteen J, Fagard R, et al. High prevalence of right ventricular involvement in endurance athletes with ventricular arrhythmias. Role of an electrophysiologic study in risk stratification. Eur Heart J 2003;24:1473-80.

43. Priori SG, Napolitano C, Memmi M, et al. Clinical and molecular characterization of patients with catecholaminergic polymorphic ventricular tachycardia. Circulation 2002;106:69-74.

44. Morshedi-Meibodi A, Evans JC, Levy D, et al. Clinical correlates and prognostic significance of exercise-induced ventricular premature beats in the community: the Framingham heart study. Circulation 2004;109:2417-22.

45. Selzman KA, Gettes LS. Exercise-Induced premature ventricular beats: should we do anything differently? Circulation 2004;109:2374-5

46. Sofi F, Capalbo A, Pucci N, et al. Cardiovascular evaluation, including resting and exercise electrocardiography, before participation in competitive sports: cross sectional study. BMJ 2008:337:a346.

47. Biffi A, Maron BJ, Verdile L, et al. Impact of physical deconditioning on ventricular tachyarrhythmias in trained athletes. J Am Coll Cardiol 2004;44:1053-8.

48. Biffi A, Maron BJ, Culasso F, et al. Patterns of ventricular tachyarrhythmias associated with training, deconditioning and retraining in elite athletes without cardiovascular abnormalities. Am J Cardiol 2011;107:697-703.

49. Biffi A, Maron BJ, Di Giacinto B, et al. Relation between training-induced left ventricular hypertrophy and risk for ventricular tachyarrhythmias in elite athletes. $A m$ Cardiol 2008;101:1792-5.

50. Delise $P$, Lanari $E$, Sitta $N$, et al. Influence of training on the number and complexity of frequent VPBs in healthy athletes. J Cardiovasc Med 2011;12:157-61.

51. Corrado D, Pelliccia A, Heidbuchel $H$, et al. Recommendations for interpretation of 12-lead electrocardiogram in the athlete. Eur Heart J 2010;31:243-59.

52. Zorzi A, Rigato I, Bauce B, et al. Arrhythmogenic right ventricular cardiomyopathy: risk stratification and indications for defibrillator therapy. Curr Cardiol Rep 2016;18:57.

53. Corrado D, Basso C, Judge DP. Arrhythmogenic cardiomyopathy. Circ Res 2017;121:784-802.

54. Corrado D, Link MS, Calkins H. Arrhythmogenic right ventricular cardiomyopathy. N Engl J Med 2017;376:61-72.

55. Basso C, Perazzolo Marra M, Rizzo S, et al. Arrhythmic mitral valve prolapse and sudden cardiac death. Circulation 2015;132:556-66.

56. Prakken NH, Cramer MJ, Olimulder MA, et al. Screening for proximal coronary artery anomalies with 3-dimensional $\mathrm{Mr}$ coronary angiography. Int J Cardiovasc Imaging 2010;26:701-10.

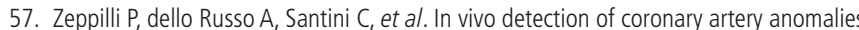
in asymptomatic athletes by echocardiographic screening. Chest 1998;114:89-93.

58. Pelliccia A, Spataro A, Maron BJ. Prospective echocardiographic screening for coronary artery anomalies in 1,360 elite competitive athletes. Am J Cardiol 1993;72:978-9.

59. Muser D, Piccoli G, Puppato M, et al. Incremental value of cardiac magnetic resonance imaging in the diagnostic work-up of patients with apparently idiopathic ventricular arrhythmias of left ventricular origin. Int J Cardiol 2015;180:142-4.

60. Schnell F, Claessen G, La Gerche A, et al. Subepicardial delayed gadolinium enhancement in asymptomatic athletes: let sleeping dogs lie? Br J Sports Med 2016;50:111-7.

61. Rademakers FE, Rogers WJ, Guier WH, et al. Relation of regional cross-fiber shortening to wall thickening in the intact heart. three-dimensional strain analysis by NMR tagging. Circulation 1994;89:1174-82. 